\title{
Numerical Study of Lightning Protection of Wind Turbine Blade with De-Icing Electrical Heating System
}

\author{
Yang Zhao ${ }^{1}$, Xi Wang ${ }^{2}$, Qibin Zhou ${ }^{3, *}$, Zhenxing Wang ${ }^{4}$ and Xiaoyan Bian ${ }^{2}$ \\ 1 School of Atmospheric Physics, Nanjing University of Information Science \& Technology, Nanjing 210044, \\ China; oceanzhao@vip.sina.com \\ 2 Electrical Engineering College, Shanghai University of Electric Power, Shanghai 200090, China; \\ wangxi@mail.shiep.edu.cn (X.W.); bianxy@shiep.edu.cn (X.B.) \\ 3 School of Mechatronics Engineering and Automation, Shanghai University, Shanghai 200444, China \\ 4 State Grid Shanghai Municipal Electric Power Company, Shanghai 200122, China; 18717721390@163.com \\ * Correspondence: zhouqibin@shu.edu.cn; Tel.: +86-13817790981
}

Received: 4 December 2019; Accepted: 1 February 2020; Published: 5 February 2020

\begin{abstract}
In order to solve the problem of icing on the surface of wind turbine blade, a heating system that includes a carbon fiber net (CFN) and power cables is proposed recently. When lightning strikes at the blade with a de-icing heating system, the blade and its heating system are more easily damaged due to the overvoltage between the lightning protection system (LPS) of the blade and the heating system. In this paper, the models of a wind turbine blade with the de-icing heating system are established by Alternative Transients Program/Electromagnetic Transients Program (ATP-EMTP) and the accuracy of models is verified through an experiment. With these models, the influence of lightning current, surge protective devices (SPDs) and earthing resistance of wind turbine are analyzed by calculating the voltage between the down-conductor of the LPS and the heating system. The results show that the voltage is positively correlated with lightning current amplitude and negatively correlated with the front time of lightning current. SPDs are quite useful to reduce the voltage, and an optimal installation scheme of SPDs is obtained by simulation. It is noted that voltage decreases slightly with the increasing earthing resistance with the optimal installation scheme of SPDs.
\end{abstract}

Keywords: wind turbine blade; de-icing electrical heating system; carbon fiber net (CFN); lightning

\section{Introduction}

The wind-power industry is developing rapidly in China. Wind farms in China are mainly distributed in the three north regions and coastal areas with abundant wind resources. In the cold winter, there is a serious problem of icing on the wind turbine blades in these areas. The change of ice-coated blade airfoil leads to the unbalance of unit load, and the output of the wind turbine blade is affected. Consequently, continuous operation will cause damage to the hub and bearing of the wind turbine. If the wind turbine is shut down to remove ice, the number of hours the wind turbine runs will be greatly reduced [1-6].

Existing de-icing solutions are divided into three categories: mechanical de-icing, coating de-icing and electric-heating de-icing. Mechanical de-icing refers to crushing ice blocks with ultrasonic wave and de-icing with centrifugal force of sudden deceleration after wind turbine blade acceleration [7-9], but this de-icing method easily causes damage to wind turbine blade. Coating de-icing is to apply hydrophobic materials on the surface of wind turbine blades $[10,11]$, but when the blade surface is defiled, the de-icing efficiency of this de-icing method is reduced. Electric-heating de-icing is to embed electric-heating elements in wind turbine blades, such as built-in copper-coils-heating de-icing [12]. 
However, when using copper-coils heating, the temperature on the blade surface is uneven, which will result in incomplete de-icing and the unbalance of wind turbine load. Currently, the newest model of the wind turbine blade de-icing method is the electric-heating method with a carbon fiber net (CFN). With this method, a CFN is embedded inside the blade surface [13] and heated by an AC power supply. This method can increase the surface temperature of the blade evenly and achieve high de-icing efficiency.

There are very few studies on its lightning protection of the electric-heating system with a CFN in the de-icing wind turbine blades, since this is quite a novel method. When lightning strikes at the air terminal of the lightning protection system (LPS) on the blades, the large lightning current will flow through the down-conductor of the LPS inside the blades. At this moment, the air between the electric-heating system and the down-conductor may be broken down by the overvoltage between them and generate arc. Consequently, not only the blade will be damaged by the high temperature and explosive effect of the arc, but, also, a partial lightning current will be injected into the electrical heating system and cause its damage- -it is even a fire hazard. In order to avoid lightning damage to the de-icing blades, it is necessary to reduce the voltage between the down-conductor and the electrical heating system from a lightning stroke.

This paper provides a numerical study on the lightning protection of the de-icing blades with the electrical heating system by using the Alternative Transients Program/Electromagnetic Transients Program (ATP-EMTP). The models of lightning, the electrical heating system and the down-conductor are built in ATP-EMTP and verified by an experiment. With these models, the voltage between down-conductor and the electrical heating system is evaluated by simulation. Surge protective devices (SPDs) and earthing resistance of wind turbine are analyzed as protection measures in the study.

\section{Wind Turbine Blade with an Electrical Heating System}

The wind turbine blade with an electrical heating system has a multilayer heat-conducting structure. Figure 1 shows the structure of a wind turbine blade cover with a CFN, and Figure 2 shows the internal down-conductor and the electrical heating system, including the CFN and power-supply cables.

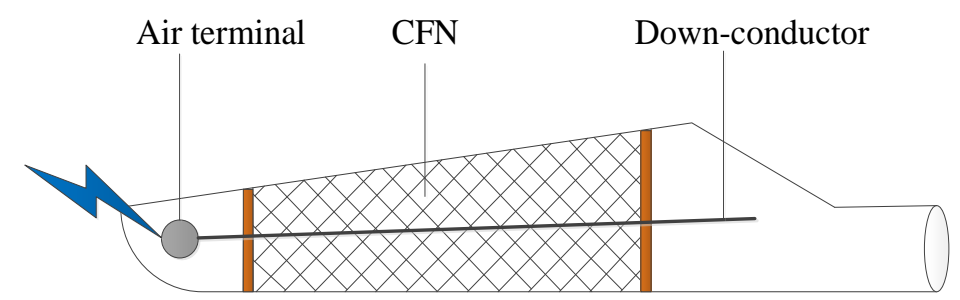

Figure 1. Structure of a wind turbine blade cover with a carbon fiber net (CFN).

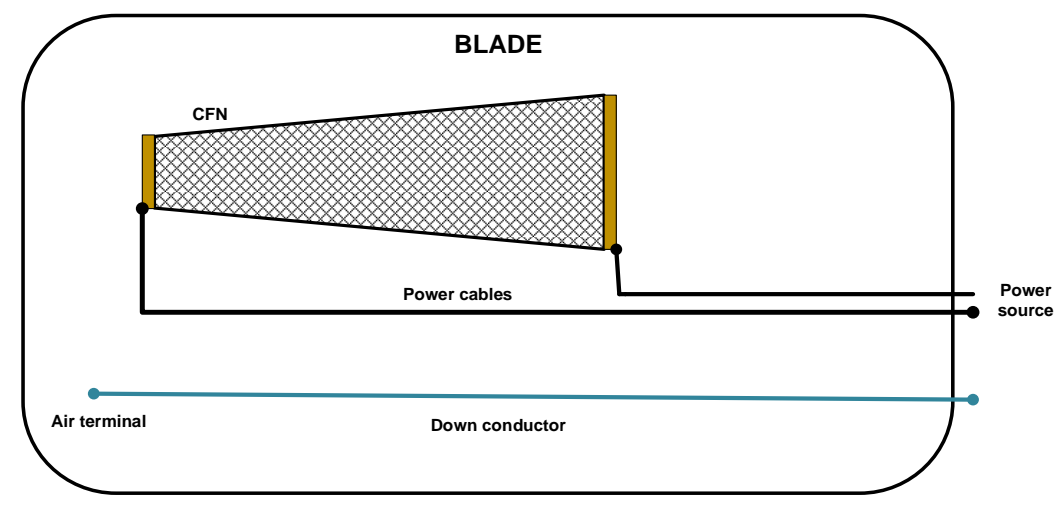

Figure 2. Configuration of down-conductor and electrical heating system. 
When the lightning strikes at a receptor of the blade's LPS, the self-inductance of the down-conductor of the LPS will generate high voltage-drop on the down-conductor during large transient lightning current flowing through it. Discharge occurs if the voltage exceeds the insulation strength of the air between the down-conductor and the electrical heating system. Consequently, the strong partial lightning current is injected into the power supply cable and CFN through the arc. The high temperature of the arc will make the air inside the blade expand suddenly and cause the blade to split or even burn. If discharge does not happen, the mutual inductance between the down-conductor and the electric-heating loop will generate induced surge current in the heating system.

\section{Modeling in ATP-EMTP}

This paper is based on a wind farm in North China. The distribution of wind turbines in Area I is shown in Figure 3. Wind turbine blades in this wind farm often suffer from freezing disasters in winter.

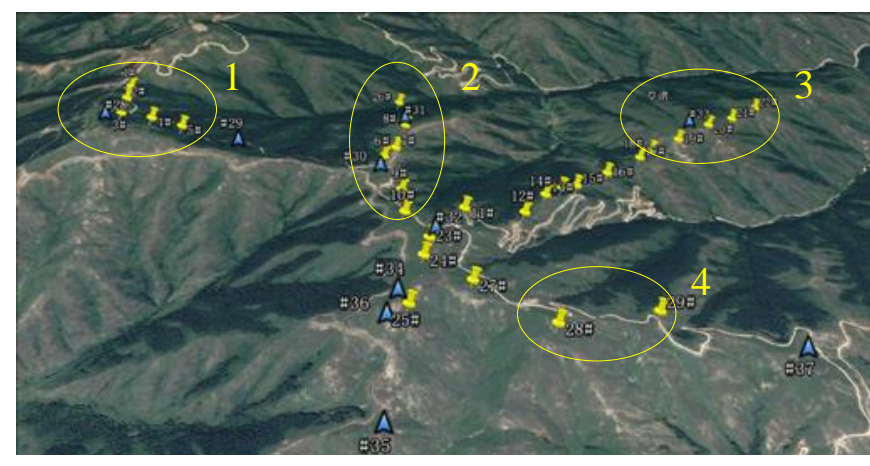

Figure 3. Geographical distribution map of wind turbines.

\subsection{Lightning Current Model}

Lightning discharge to the earth is a complex process, including leader, return stroke and subsequent return stroke. Lightning current is generally expressed by three parameters: current amplitude $\left(I_{m}\right)$, front time $\left(T_{1}\right)$ and wavelength time $\left(T_{2}\right)$. Studies have shown that the amplitude of the lightning current and the front time have a direct impact on the induced overvoltage.

There are 30 wind turbines in the wind farm. According to the principle of similar geographical position and different altitude, the wind turbines are divided into four sections, as shown in Figure 3. Table 1 shows the distribution of ground flash density and the average current amplitude recorded by the Lightning Location System (LLS).

Table 1. Ground flash density and average current amplitude.

\begin{tabular}{ccc}
\hline Section & Ground Flash Density $\left(\right.$ times $\left./ \mathbf{k m}^{\mathbf{2}} \cdot \mathbf{a}\right)$ & Average Current Amplitude (kA) \\
\hline 1 & 6.067 & 43.300 \\
2 & 3.231 & 45.575 \\
3 & 2.500 & 36.800 \\
4 & 4.146 & 35.078 \\
\hline
\end{tabular}

At present, there are three common lightning current mathematical models: the double exponential function model, the Heidler model and the impulse function model [14]. Among them, the Heidler model is more suitable for the study of lightning currents in mountainous areas. Therefore, this paper chooses this model for electromagnetic simulation about lightning's transient effects in wind farms. 


\subsection{CFN Model}

A CFN is laid on the wind turbine blade with the same shape of the blade surface. Considering that the change of the diameter of a CFN from top to bottom is much smaller than its own length, it is simplified as a hollow conical model, as shown in Figure 4.

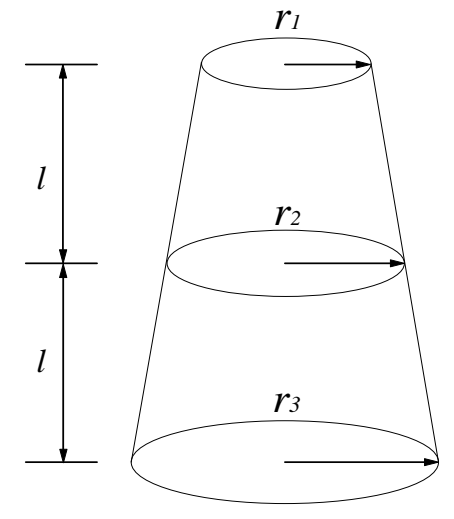

Figure 4. Simplified model of a CFN.

The equivalent radius of a CFN can be calculated by Equation (1):

$$
r_{\text {carbon }}=\frac{r_{1} l+2 r_{2} l+r_{3} l}{4 l}
$$

where $l$ is half of the total length of the CFN; $r_{1}$ is the radius at the top of the CFN; $r_{2}$ is the radius of the middle part of CFN; and $r_{3}$ is the radius at the bottom of the CFN.

The formulas for calculating resistance, inductance and capacitance of a CFN are as follows [15]:

$$
\begin{gathered}
R_{C F N}=\rho_{l} \frac{2 l}{S} \\
L_{C F N}=\frac{2 \mu_{0} l}{2 \pi}\left(\ln \frac{2 \pi}{r_{C F N}}-1-\frac{\mu}{\mu_{0}} \ln B\right) \\
C_{C F N}=\frac{\rho \varepsilon_{0}}{R l}
\end{gathered}
$$

where $\rho_{l}$ is the resistivity of the CFN; $\mu_{0}$ is the permeability of vacuum; $\mu$ is the relative permeability; $B$ is the ratio of inner radius to outer radius of tower; $\rho$ is the soil resistivity; and $\varepsilon_{0}$ is the permittivity of vacuum.

In order to simulate the wave process of lightning propagation on the CFN, the $\mathrm{CFN}$ is equivalent to the wave impedance model and is segmented according to the principle that the segment length is less than $1 / 10$ of the minimum wavelength corresponding to the maximum frequency of the lightning current [16]. The CFN is equivalent to an equivalent circuit in which a plurality of wave impedance is connected in series. The CFN is divided into six segments, each segment having a length of $4.98 \mathrm{~m}$.

\subsection{Power-Cable Model}

The type of $690 \mathrm{~V}$ power-supply cable of the heating system is YJV-1*240. It is a single core cable, without shielding layer. This cable is modeled by the transmission line modelling tool LCC in ATP [17]. The length of the cable is $95 \mathrm{~m}$, and its equivalent impedance is $100 \Omega$.

\subsection{SPD Model}

An SPD is a device in low-voltage power systems that is used to limit transient overvoltage and divert surge currents. When a single SPD cannot effectively protect the power system, it is necessary 
to install multilevel SPDs to form cascaded protection cooperation, to protect the safe operation of equipment [18]. Three SPD cooperation modes for low-voltage power-distribution systems are listed in IEC 61643-12 [19], including the coordination of voltage-switching SPDs and voltage-switching SPDs, the coordination of voltage-limiting SPDs and voltage-limiting SPDs, and the coordination of voltage-switching SPDs and voltage-limiting SPDs. Among them, voltage-limiting SPDs, which are composed of nonlinear resistors, can avoid the power frequency follow current of voltage-switching SPDs. In this paper, the combination of voltage-limiting SPDs and voltage-limiting SPDs is studied. The total length of the CFN in the blade shown in Figure 1 that is $29.9 \mathrm{~m}$. Considering the possible disconnection of power cables and SPDs at both ends of the CFN, this paper adopts the scheme of installing SPDs at both ends of the CFN.

The volt-ampere characteristic of the SPD used in this paper is shown in Table 2 and simulated by the MOV model in ATP-EMTP.

Table 2. Volt-ampere characteristics of a surge protective device (SPD).

\begin{tabular}{ccc}
\hline Device & $\mathbf{I}_{\mathbf{n}} / \mathbf{k} \mathbf{A}$ & $\mathbf{U}_{\mathbf{p}} / \mathbf{V}$ \\
\hline & 1 & 1200 \\
SPD & 5 & 2400 \\
& 10 & 2800 \\
& 15 & 3000 \\
\hline
\end{tabular}

\section{Experimental Verification}

In order to verify the modeling approach of the down-conductor and the heating system, an experiment was conducted in the lab. The layout of the experiment is shown in Figure 5.

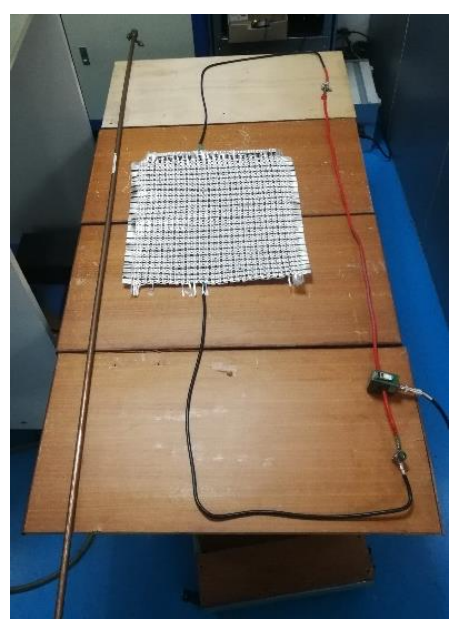

(a) Real experiment setup

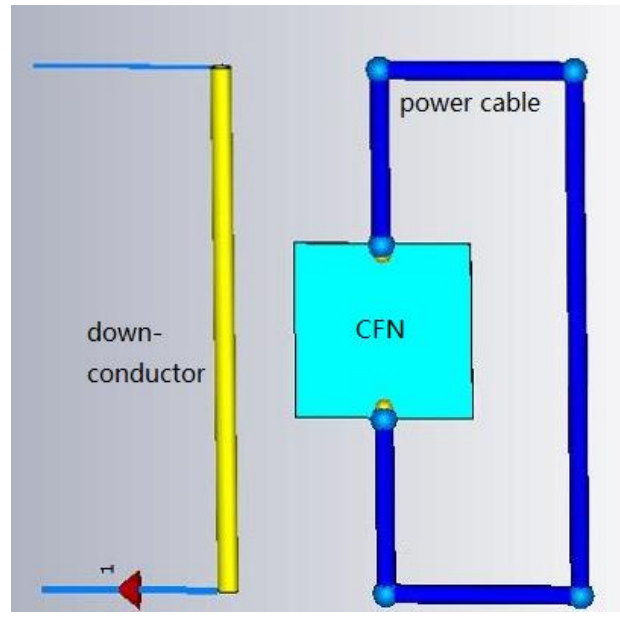

(b) Illustration of the experiment setup

Figure 5. Experiment setup and illustration.

As Figure 5 shows, a copper bar was used to simulate the down-conductor of the LPS. An electrical loop was built with a real CFN and two cables. The power source was considered as short-circuit under surge circumstance because its internal impedance is much smaller than the CFN.

During the experiment, the impulse current generator outputted an $11.80 \mathrm{kA} 10 / 350 \mu$ s surge current. The surge current flowed through the copper bar. The induced current in the CFN loop was measured by a Rogowaski coil, as shown in Figure 5a.

Figure 6a illustrated the measured induced current in the electric circuit with the CFN. Figure 6b is the calculated result from the models built in ATP-EMTP. 


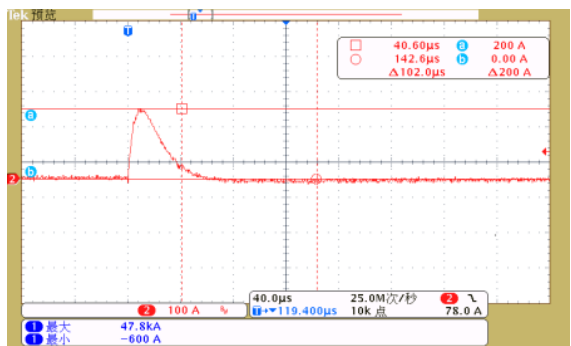

(a) Measured induced current

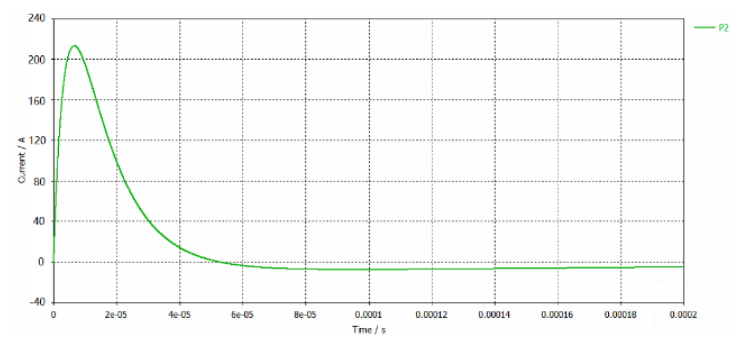

(b) Calculated induced current

Figure 6. Comparison between the measured and calculated induced current.

From Figure 6, it is noted that the calculated result from the model built in ATP-EMTP is almost the same as the measured value with an error less than $5 \%$. Then it is verified that the built models in ATP-EMTP can be used to study the lightning protection, as follows.

\section{Simulation Results and Analysis}

\subsection{Effect of Lightning Current Amplitude and Front Time}

In order to study the influence of the lightning current front time on the voltage between the down-conductor and the CFN under different lightning-current amplitudes, the earthing resistance of the wind turbine is $10 \Omega$. The lightning current amplitudes are 10,50, 100 and $200 \mathrm{kA}$, respectively. The lightning-current waveforms are 1.2/50, 2.6/50, 8/50 and 20/50 $\mu$ s, respectively [20]. The simulation results are shown in Table 3. It can be seen from the table that, when the front time of the lightning current is constant, voltage value is approximately positively correlated with the amplitude of lightning current; when the amplitude of the lightning current is constant, voltage value decreases rapidly with the increase of the front time of the lightning current.

Table 3. Voltage between the down-conductor and CFN.

\begin{tabular}{ccccc}
\hline \multirow{2}{*}{ Amplitude of Lightning Current /kA } & \multicolumn{3}{c}{ Voltage between the Down-Conductor and CFN/MV } \\
\cline { 2 - 5 } & $\mathbf{1 . 2 / 5 0} \boldsymbol{\mu s}$ & $\mathbf{2 . 6 / 5 0} \boldsymbol{\mu s}$ & $\mathbf{8 / 5 0} \boldsymbol{\mu s}$ & $\mathbf{2 0 / 5 0} \boldsymbol{\mu s}$ \\
\hline 10 & 0.62 & 0.37 & 0.19 & 0.06 \\
50 & 3.14 & 1.84 & 0.95 & 0.34 \\
100 & 6.24 & 3.69 & 1.91 & 0.69 \\
200 & 12.8 & 7.38 & 3.68 & 1.38 \\
\hline
\end{tabular}

When the amplitude of lightning current is $50 \mathrm{kA}$, overvoltage of down-conductor and the CFN at different front times are shown in Figure 7. It can be seen from Figure 7 that, when the lightning current front time is $1.2 / 50 \mu \mathrm{s}$, the voltage between the down-conductor and the CFN reaches the peak value of $3.14 \mathrm{MV}$, in which the overvoltage on the down-conductor is $3.03 \mathrm{MV}$ and the induced voltage value of the CFN is only $110 \mathrm{kV}$. That is to say, there is no obvious induced overvoltage in the CFN when the down-conductor overvoltage reaches its peak value. The longer the front time is, the closer the peak time of lightning voltage on the down-conductor is to the peak time of induced voltage of the CFN. Based on the above simulation results and the measured waveforms of lightning currents in China, the lightning current with a front time of $2.6 / 50 \mu \mathrm{s}$ and amplitude of $50 \mathrm{kA}$ is selected for future study. 


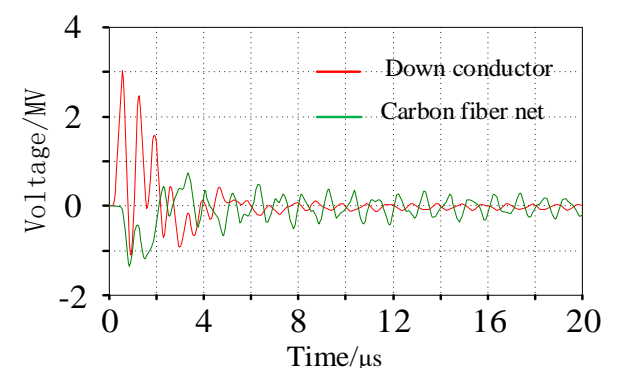

(a) $1.2 / 50 \mu \mathrm{s}$

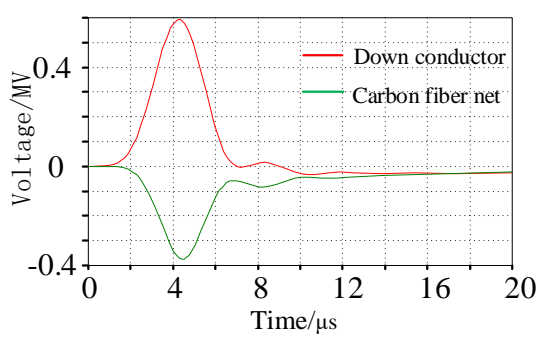

(c) $8 / 50 \mu \mathrm{s}$

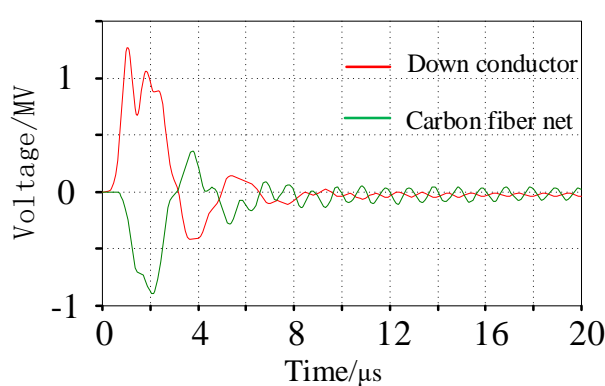

(b) $2.6 / 50 \mu \mathrm{s}$

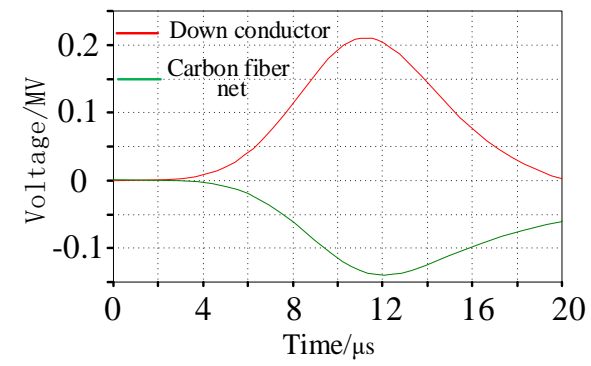

(d) $20 / 50 \mu \mathrm{s}$

Figure 7. Overvoltage of down-conductor and the CFN at different front times.

\subsection{Effect of SPD Installation Location and Number}

In order to limit the voltage between the down-conductor and CFN, SPDs can be used. The scheme of installing an SPD at both ends of the CFN is adopted. Six installation schemes are set up, as shown in Table 4 and Figure 8.

Table 4. SPD installation scheme.

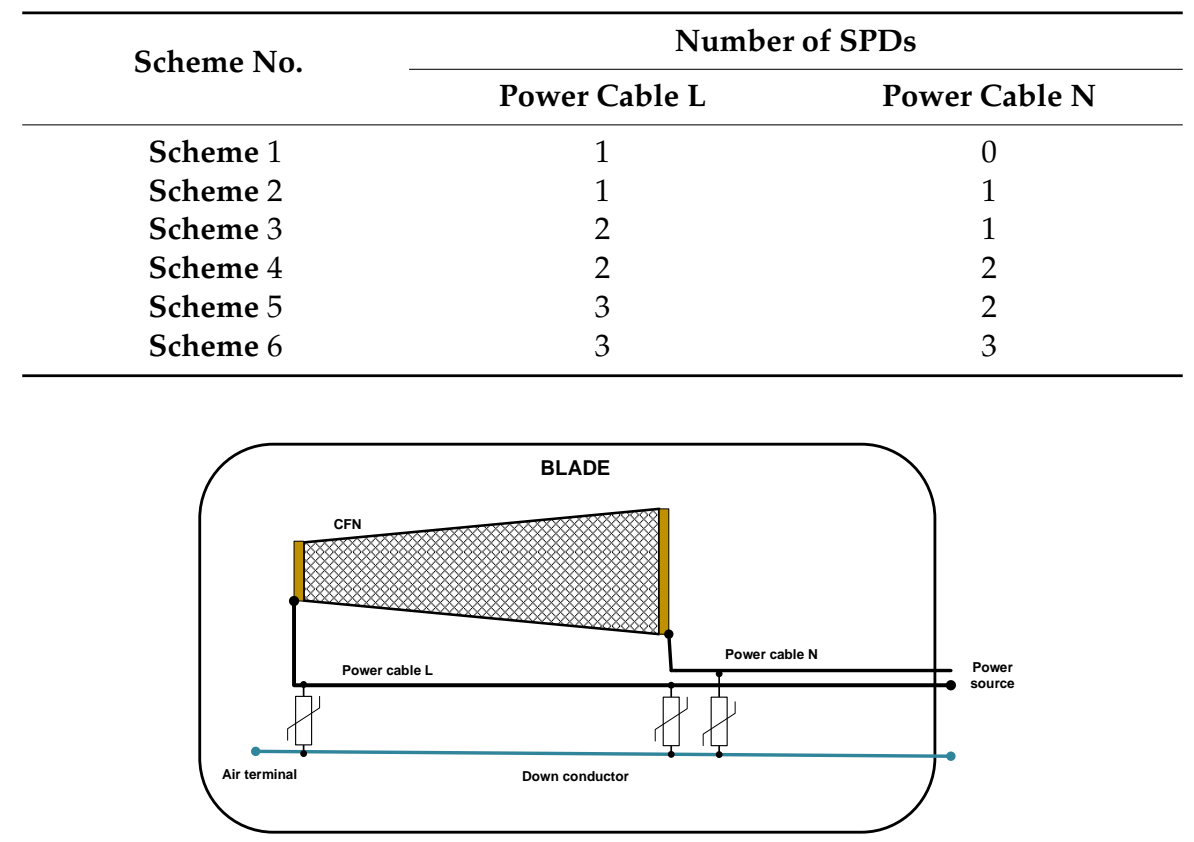

Figure 8. Scheme 3 of SPD installation.

Taking the earthing resistance of the wind turbine as $10 \Omega$, the lightning current with the front time of 2.6/50 $\mu$ s and the amplitude of $50 \mathrm{kA}$, the above six schemes are simulated, respectively. The 
voltage between the down-conductor and CFN with different SPD installation schemes is shown in Figure 9. The voltage between the down-conductor and CFN is shown in Table 5.

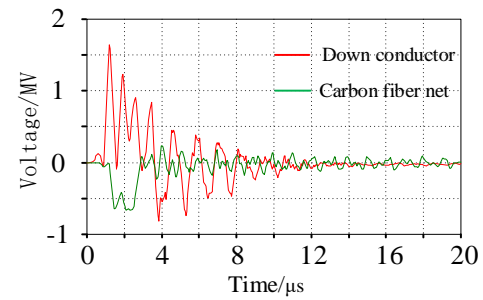

(a) Scheme 1

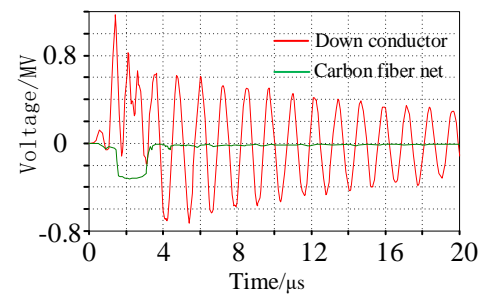

(c) Scheme 3

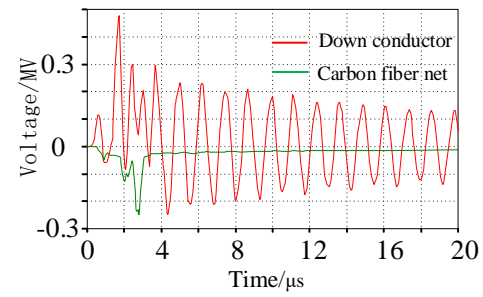

(e) Scheme 5

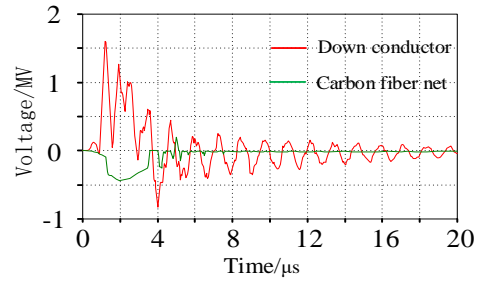

(b) Scheme 2

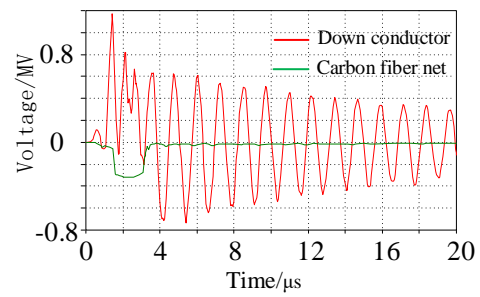

(d) Scheme 4

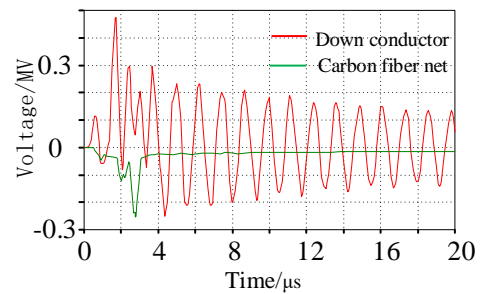

(f) Scheme 6

Figure 9. Voltage between the down-conductor and CFN with various installation schemes.

Table 5. Voltage between the down-conductor and CFN with various installation schemes.

\begin{tabular}{cc}
\hline Scheme No. & Difference of Overvoltage between Down-Conductor and Carbon Fiber/MV \\
\hline Scheme 1 & 1.66 \\
Scheme 2 & 1.65 \\
Scheme 3 & 1.19 \\
Scheme 4 & 1.10 \\
Scheme 5 & 0.51 \\
Scheme 6 & 0.49 \\
\hline
\end{tabular}

By comparing Figure $9 \mathrm{~b}$ with Figure 9c, it can be found that, when the number of SPDs of the power cable $\mathrm{N}$ of the CFN is constant, increasing the number of SPDs of the power cable L can greatly reduce the voltage between the down-conductor and the CFN. Moreover, the same result can be obtained by comparing Figure 9d with Figure 9e. However, by comparing Figure 9a with Figure 9b, it can be found that when the number of SPDs of power cable L is constant, increasing the number of SPDs of power cable $\mathrm{N}$ has no significant effect on reducing the voltage between the down-conductor and CFN. By comparing Figure $9 \mathrm{c}$ with Figures $9 \mathrm{~d}$ and $9 \mathrm{e}$ with Figure $9 \mathrm{f}$, we can get the same result.

When Figure 9e or Figure 9f is adopted, the induced overvoltage between the lead and CFN is about $0.51 \mathrm{MV}$, which is not only lower than the insulation threshold calculated in this paper, but also has enough insulation margin. Therefore, this paper proposes that the wind farm adopts an SPD lightning protection scheme at both ends of the CFN in the subsequent design of the de-icing blade. Considering the economy of wind-farm construction, Figure 9e is adopted, and the complete installation is shown in Figure 10. 


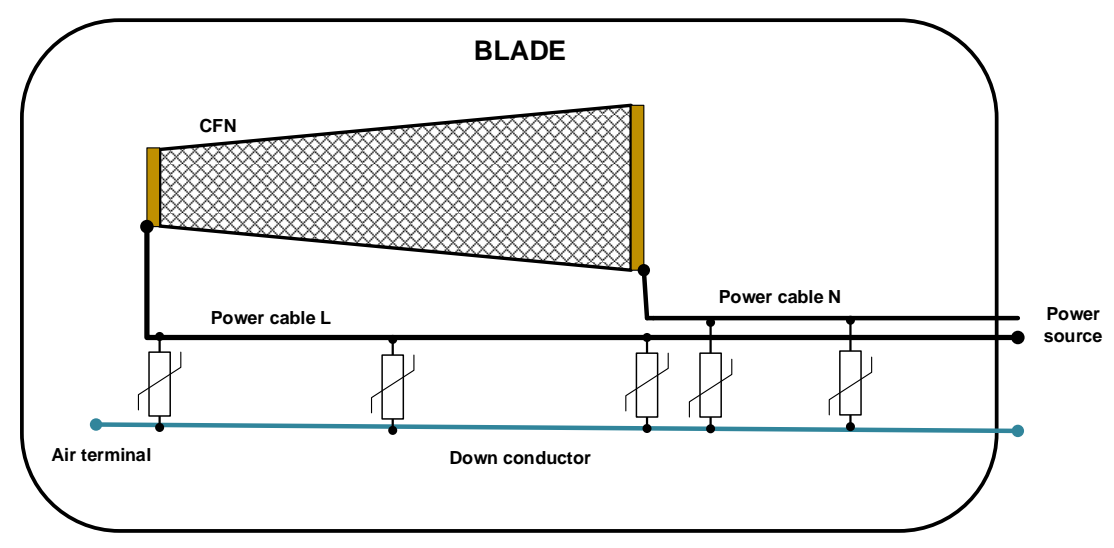

Figure 10. Optimized SPD installation scheme.

\subsection{Effect of Earthing Resistance}

In order to analyze the effect of earthing resistance on difference of overvoltage between the down-conductor and CFN, this paper takes the lightning current with front time of 2.6/50 $\mu$ s and amplitude of $50 \mathrm{kA}$, and the earthing resistance of the wind turbine is set to $2,4,6,8$, and $10 \Omega$, respectively. The blade without an SPD and Figure 9e were studied, and the calculation results are shown in Figure 11. When Figure 9e or Figure 9f is adopted, the induced voltage between the lead and CFN is about $0.51 \mathrm{MV}$, which is not only lower than the insulation threshold calculated in this paper, but also has enough insulation margin. Therefore, it is proposed that the wind farm adopts an SPD lightning protection scheme at both ends of the CFN in the subsequent design of the de-icing blade. Considering the economy of wind-farm construction, Figure 9e is adopted, and the complete installation is shown in Figure 10.

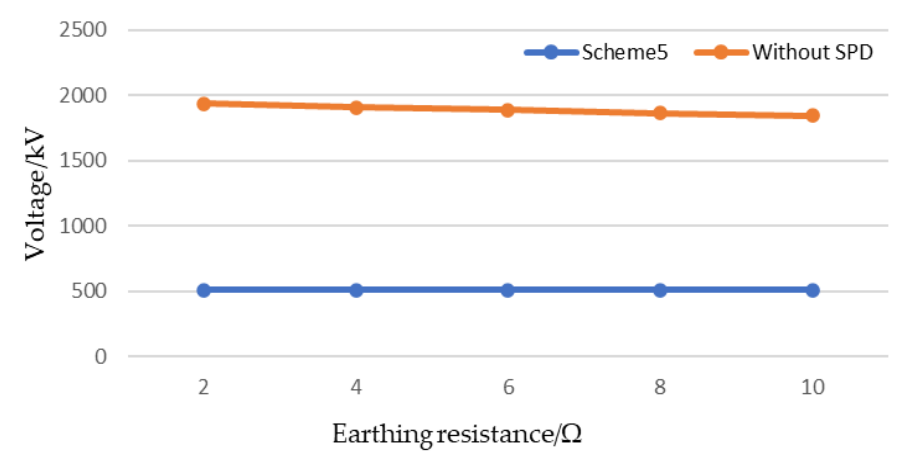

Figure 11. Effect of earthing resistance on difference of overvoltage between the down-conductor and CFN.

It can be seen from Figure 11 that, when the blade is not installed with an SPD, the voltage between the down-conductor and CFN decreases slightly with the increase of earthing resistance. For each increase of earthing resistance of $2 \Omega$, the voltage decreases by tens of kilovolts. When Figure 9e is adopted for the blade, even if the earthing resistance of the wind turbine changes, the difference of induced overvoltage between the down-conductor and the CFN is almost unchanged.

However, this conclusion does not mean that the difference of induced overvoltage between the down-conductor and the CFN can be reduced by increasing the earthing resistance, because the ground potential at the base of the tower rises to a very high level after increasing the earthing resistance, which will make the electronic equipment in the wind turbine face a more severe lightning risk. 


\section{Conclusions}

In this paper, the models of wind turbine blade and $690 \mathrm{~V}$ power supply circuit are established by using ATP-EMTP. The following conclusions can be obtained from the simulation results.

(1) When the front time of lightning current remains unchanged, the voltage between the down-conductor and CFN is positively correlated with the lightning current amplitude. When the lightning current amplitude remains unchanged, the voltage decreases rapidly with the increase of the front time of lightning current.

(2) The installation of SPDs between the down-conductor and CFN can significantly reduce the voltage, and is affected by the installation location and SPD number. When the blade is not equipped with a SPDs, the voltage is as high as $1.84 \mathrm{MV}$; when the installation method of the Figure $9 \mathrm{e}$ is adopted, the overvoltage value is reduced to $0.51 \mathrm{MV}$, which satisfies the blade insulation requirement.

(3) When the blade is not equipped with SPDs, the voltage decreases slightly with the increase of grounding resistance, and its order of magnitude is tens of kilovolts. When Figure 9e is adopted for the blade, even if the earthing resistance of the wind turbine changes, the induced voltage between the down-conductor and CFN is almost unchanged.

With the above conclusions, it is suggested that the scheme of equipotential bonding proposed for the lightning protection of wind turbine de-icing blades has important significance as a guide for future engineering practice.

Author Contributions: Conceptualization, Q.Z.; methodology, X.W.; software, X.W.; validation, Y.Z.; formal analysis, Q.Z.; investigation, X.W.; writing—original draft preparation, Z.W.; writing-review and editing, Y.Z. and X.W.; supervision, X.B.; project administration, Q.Z.; funding acquisition, Y.Z. All authors have read and agreed to the published version of the manuscript.

Funding: This research was financially supported by the Shanghai Science and Technology Project, under a grant (16020501000), and the "Shuguang Program" of Shanghai Municipal Education Commission (15SG50), and Shanghai Meteorological Bureau Project (MS201602).

Conflicts of Interest: The authors declare no conflicts of interest. The funders had no role in the design of the study; in the collection, analyses, or interpretation of data; in the writing of the manuscript; or in the decision to publish the results.

\section{References}

1. Davis, N.N.; Pinson, P.; Hahmann, A.N.; Clausen, N.E.; Zagar, M. Identifying and characterizing the impact of turbine icing on wind farm power generation. Wind Energy 2016, 19, 1503-1518. [CrossRef]

2. Shu, L.C.; Liang, J.; Hu, Q.; Jiang, X.L.; Ren, X.K.; Qiu, G. Study on small wind turbine icing and its performance. Cold Reg. Sci. Technol. 2017, 134, 11-19. [CrossRef]

3. Yin, Z.; Si, W.R.; Fu, C.Z.; Lu, Q.Y.; Lu, M.X.; Jiang, A.F.; Fu, Z.C. Lightning Detection and Location System for Shanghai Power Grid. In Proceedings of the 2014 International Conference on Power and Energy, Beijing, China, 29-30 November 2014.

4. Elistratov, V.; Denisov, R. Justification of Wind Turbine Operation and Management Modes for Russian Arctic Conditions. In Proceedings of the 2017 International Conference on Industrial Engineering, Applications and Manufacturing (ICIEAM), Chelyabinsk, Russia, 16-19 May 2017.

5. Shu, L.C.; Li, H.T.; Hu, Q.; Jiang, X.L.; Qiu, G.; McClure, G.; Yang, H. Study of ice accretion feature and power characteristics of wind turbines at natural icing environment. Cold Reg. Sci. Technol. 2018, 147, 45-54. [CrossRef]

6. Fakorede, O.; Feger, Z.; Ibrahim, H.; Ilinca, A.; Perron, J.; Masson, C. Ice protection systems for wind turbines in cold climate: Characteristics, comparisons and analysis. Renew. Sustain. Energy Rev. 2016, 65, $662-675$. [CrossRef]

7. Yin, C.B.; Zhang, Z.D.; Wang, Z.J.; Guo, H. Numerical simulation and experimental validation of ultrasonic de-icing system for wind turbine blade. Appl. Acoust. 2016, 114, 19-26. [CrossRef] 
8. Daniliuk, V.; Xu, Y.M.; Liu, R.B.; He, T.P.; Wang, X. Ultrasonic de-icing of wind turbine blades: Performance comparison of perspective transducers. Renew. Energy 2020, 145, 2005-2018. [CrossRef]

9. Wang, Y.B.; Xu, Y.M.; Lei, Y.Y. An effect assessment and prediction method of ultrasonic de-icing for composite wind turbine blades. Renew. Energy 2018, 118, 1015-1023. [CrossRef]

10. Shen, Y.Z.; Tao, H.J.; Chen, S.L.; Zhu, L.M.; Wang, T.; Tao, J. Icephobic/anti-icing potential of superhydrophobic Ti6Al4V surfaces with hierarchical textures. RSC Adv. 2015, 5, 1666-1672. [CrossRef]

11. Zhao, Z.H.; Chen, H.W.; Liu, X.L.; Liu, H.; Zhang, D.Y. Development of high-efficient synthetic electric heating coating for anti-icing/de-icing. Surf. Coat. Technol. 2018, 349, 340-346. [CrossRef]

12. Chavan, D.S.; Yadav, R.; Singh, A.; Sankpal, J.; Mishra, S.K. Ice Elimination from Wind Turbine Blade using Induction Heating. In Proceedings of the 2017 International Conference on Energy, Communication, Data Analytics and Soft Computing (ICECDS), Chennai, India, 1-2 August 2017; pp. 2702-2706.

13. Li, L.C.; Cui, X.; Wu, Z.H.; Zeng, J.C.; Xing, S.L. A method of eliminating ice on wind turbine blade by using carbon fiber composites. Adv. Mater. Res. 2013, 774-776, 1322-1325. [CrossRef]

14. Rakov, V.A. Lightning Parameters for Engineering Applications (Keynote Speech). In Proceedings of the 2010 Asia-Pacific Symposium on Electromagnetic Compatibility (APEMC), Beijing, China, 12-16 April 2010; pp. 1120-1123.

15. Lynch, A.C. Inductance Calculations. Nature 1949, 163, 195. [CrossRef]

16. Zou, J.; Lee, J.; Ji, Y.F.; Chang, S.; Zhang, B.; He, J.L. Transient Simulation Model for a Lightning Protection System Using the Approach of a Coupled Transmission Line Network. IEEE Trans. Electromagn. Compat. 2007, 49, 614-622. [CrossRef]

17. Ali, S.A. Modeling of power networks by ATP-Draw for harmonics propagation study. Trans. Electr. Electron. Mater. 2013, 14, 283-290. [CrossRef]

18. Kisielewicz, T.; Piparo, G.L.; Fiamingo, F.; Mazzetti, C.; Kuca, B.; Flisowski, Z. Factors affecting selection, installation and coordination of surge protective devices for low voltage systems. Electr. Power Syst. Res. 2014, 113, 220-227. [CrossRef]

19. IEC 61643-12. Low-Voltage Surge Protective Devices_Part 12: Surge Protective Devices Connected to Low-Voltage Power Distribution Systems—Selection and Application Principles; International Electrotechnical Commission (IEC): Geneva, Switzerland, 2008; pp. 1-154.

20. IEC 62305-1. Protection against Lightning-Part 1: General Principles; International Electrotechnical Commission (IEC): Geneva, Switzerland, 2010; pp. 1-67. 